\title{
ESTRATÉGIA DO OCEANO AZUL: RELATO DE IMPLANTAÇÃO EM UM SETOR EM CRISE
}

\section{RESUMO}

Este artigo apresenta alguns dos elementos facilitadores e dificultadores para se implantar a metodologia Estratégia do Oceano Azul (EOA). A empresa estudada passava por uma situação competitiva intricada, com redução de demanda e excesso de oferta. Com o uso de alguns dos pressupostos da EOA, a empresa redefiniu estratégias competitivas reduzindo sua exposição à rivalidade tipicamente encontrada em setores maduros. Este artigo narra a construção da curva de valor, que tomou 540 horas em entrevistas, contou com a participação de um dos autores e envolveu diversos grupos de foco. Como resultados, entre outros elementos, destaca-se a importância da criação de sentido (sensemaking) e da heterogeneidade de fontes de informação. Diante da riqueza dos achados, considera-se que este artigo contribui para o campo da Estratégia Empresarial. Entre outros, descreve a formação das equipes, mecanismos de coleta de dados e desenvolvimento da curva de valor. O método para desenvolvimento desse artigo baseou-se na pesquisa-ação conduzida pelos autores durante o desenvolvimento do projeto EOA. Foram também conduzidas entrevistas e consultadas fontes secundárias de dados.

Palavras-chave: Curva de valor; Estratégia do oceano azul; Formação de estratégias.

\section{BLUE OCEAN STRATEGY: IMPLEMENTATION REPORT IN A SECTOR IN CRISIS}

\begin{abstract}
This paper presents some drivers and obstacles for implementing the Blue Ocean Strategy methodology (BOS). The company studied underwent a complex competitive environment, with reduced demand and supply excess. With the use of some of the assumptions of the BOS, the company redefined its competitive strategies and reduced its exposure to the rivalry usually found in mature industries. This paper presents the construction of the value curve, which took 540 hours of interviews and various focus groups. As a result, among other things, it highlights the importance of sensemaking and the diversity of information sources. Given these findings, it is considered that this paper contribute to the field of Business Strategy. Among others, the report describes the formation of teams, data collection mechanisms and development of value curve. The method for developing this article was based on an action research conducted by the authors during the development of EOA project. Besides the use of such a method, interviews and secondary data analysis were conducted.
\end{abstract}

Keywords: Blue Ocean Strategy, Strategy Formulation and Value Curve. 
ESTRATEGIA DEL OCÉANO AZUL: INFORME SOBRE LA EJECUCIÓN EN UNA INDUSTRIA EN CRISIS

\section{RESUMEN}

Este artículo presenta algunos de los facilitadores y dificultando desplegar la metodología Estrategia del Océano Azul (EOA). La empresa estudiada pasó por una situación competitiva intrincada, con una demanda reducida y el exceso de oferta. Con el uso de algunos de los supuestos de la EOA, la empresa redefinió estrategias competitivas mediante la reducción de su exposición a la rivalidad se encuentran típicamente en industrias maduras. El artículo relata la construcción de la curva de valor, que tuvo 540 horas de entrevistas, se asistió a uno de los autores y participan varios grupos de enfoque. Como resultado, entre otras cosas, pone de relieve la importancia de la creación de sentido (sensemaking) y la heterogeneidad de las fuentes de información. Frente a la riqueza de los hallazgos, se considera que este trabajo contribuirá al campo de la estrategia empresarial. Entre otros, se describe la formación de equipos, mecanismos de recolección de datos y el desarrollo de la curva de valor. El método para el desarrollo de productos se basa en la investigación-acción llevada a cabo por los autores durante el desarrollo del proyecto EOA. También se realizaron entrevistas y fuentes de datos secundarias consultadas.

Palabras clave: Estrategia del Océano Azul; Estrategia de Capacitación; Valor de la Curva.

Edson Ricardo Barbero ${ }^{1}$ Bruno Nascimento Vieira ${ }^{2}$

\footnotetext{
${ }^{1}$ Doutor em Administração pela Universidade de São Paulo - USP. Professor do Mestrado Profissional da Fecap. Brasil.E-mail: barberoedson@gmail.com

${ }^{2}$ Fundação Instituto de Administração - FIA. Brasil. E-mail: brunonv@ gmail.com
} 


\section{INTRODUÇÃO}

$\mathrm{O}$ anseio central desse artigo é descrever a implementação de algumas das metodologias preconizadas no arcabouço teórico Estratégia do Oceano Azul (Kim \& Mauborgne, 2005) em uma empresa do setor siderúrgico, entre os anos 2012 e 2013. Mais particularmente, apresentam-se os principais facilitadores e dificultadores desta implementação por sigilo, sem, contudo, adentrar-se no conteúdo particular das estratégias da empresa. A ênfase será, portanto, no processo de formação das estratégias. Os parágrafos seguintes discorrem acerca das particularidades e dos objetivos desse artigo.

Este artigo tem caráter tecnológico e, como tal, trata do produto final de uma pesquisa técnica que descreve uma experiência original (Biancolino, Kniess, Maccari \& Rabechini Jr., 2012). A situação-problema na qual a firma se situava era aquela típica do setor siderúrgico em 2012: forte queda na demanda, achatamento das margens e incremento da rivalidade internacional. A situação exigia uma solução que, $a$ priori, poderia ser solucionada, ao menos em parte, pelos pressupostos da EOA. O arcabouço conceitual, denominado EOA, procura transformar o tema Estratégica Competitiva substituindo a centralidade da Vantagem Competitiva por Inovação de Valor como seu conceito basilar (Burke, Van Stel \& Thurik, 2008). Contrapondo-se aos autores da orientação EstruturaConduta-Desempenho, Kim e Mauborgne (2005) contestam a posição dominante que a concorrência assumiu na gestão estratégica.

Apesar da pujança encontrada em publicações, há críticas quanto a aplicabilidade da EOA. Isto porque parece simples compreender os casos debatidos na obra, mas se critica a dificuldade - de modo ex-ante de se implementar as ferramentas propugnadas. Com isso em mente, o anseio principal desse relato técnico é apresentar a implementação de algumas das técnicas da EOA em uma empresa multinacional de grande porte, situada em um setor em maturidade e com redução de margens de lucro (setor siderúrgico).

Mais particularmente, visa-se a indicar os principais fatores facilitadores e dificuldades que surgem ao se empreender esforços neste sentido. A questão que dirige o trabalho é a seguinte: Que métodos e etapas podem ser considerados bemsucedidos ao se levar a cabo formulações estratégicas com base no arcabouço da EOA?

O caso deste relato foi desenvolvido no Brasil em uma siderúrgica que será retratada como empresa Alfa. Neste caso, desenvolveu-se uma nova curva de valor para empresa, por meio de um processo sequencial, mas com forte presença de incrementalismo e geração de sentido. Como detalhado nesse artigo, foram empreendidas muitas entrevistas e grupos de foco para levar a cabo a implementação da EOA. Almeja-se que este trabalho auxilie futuros projetos em que se deseje implementar a EOA, sobretudo em ramos de commodities. Ao se desenvolver estratégias em tais indústrias, é comum se enfatizar decisões que maximizem a eficiência operacional, dado que as possibilidades de agregação de valor ao cliente se tornam escassas (Greenwald \& Kahn, 2005). Justificase nesse artigo, em complemento, porque não se encontrou um número significativo de casos que relatam a aplicação prática da EOA diante dos desafios de um setor maduro.

As justificativas para este artigo, porém, não se exaurem na inexistência de estudos empíricos. A contribuição evidencia-se também pela significativa importância do setor siderúrgico. Tal ramo emprega no Brasil, em 2015, quase 130 mil pessoas, sendo o sexto maior exportador de aço do mundo (Instituto Aço Brasil, 2015). A demonstração de práticas implementadas em um contexto real é, por fim, importante justificativa. Empresas que enfrentem desafios semelhantes podem utilizar o detalhamento metodológico aqui exposto para facilitar seu processo de formulação estratégica usando as teorias da EOA.

Os próximos itens demonstram uma síntese do contexto e da realidade investigada. Detalha-se a situação competitiva do ramo siderúrgico. Demonstrase também as circunstâncias vivenciadas pela empresa Alfa em 2012-2013. Posteriormente, apresenta-se as etapas e métodos empreendidos e se sintetiza, ao final, as principais recomendações práticas. Para Biancolino, Kniess, Maccari e Rabechini Jr. (2012, p. 296), um artigo tecnológico deve "[...]refletir o pensamento do autor[...]", "[...]não tem por objetivo apresentar de forma pura e simples fatos ocorridos[...]" e "[...]privilegia o conhecimento prescritivo".

O método para a construção deste trabalho fundamentou-se na participação de um dos autores como executivo atuante no projeto EOA da empresa Alfa. A esta participação complementou-se um conjunto de entrevistas com outros membros do time responsável pelo projeto EOA. Foram entrevistados 10 executivos envolvidos no processo. As entrevistas foram do tipo semiestruturadas e duraram entre $60 \mathrm{e}$ 120 minutos. Consultou-se também dados secundários sobre o setor, empresa e documentos da empresa. As entrevistas procuraram contemplar a multiplicidade de fontes de informação e permitir triangulação dos dados coletados; para tanto, foram entrevistados profissionais de diversas áreas e pontos de vistas. Como forma de incorporar elucidações teóricas e enriquecer as análises, o conteúdo deste trabalho foi debatido em sala de aula e em reuniões com professor orientador (um dos autores deste artigo) no contexto de um curso de Pós-Graduação.

Ainda no tocante ao método, as entrevistas foram conduzidas por meio de um instrumento fundamentado na teoria da EOA. Mais particularmente, construiu-se um roteiro de entrevistas a partir de Kim e Mauborgne (2009). Além da descrição do projeto em 
si, segundo as múltiplas fontes de informação, o instrumento de coleta direcionou os respondentes a indicar os obstáculos encontrados e os fatores que facilitaram a construção da curva e que poderiam ser listados como lições aprendidas. Os autores, ao desenvolver este material, aplicaram diversas habilidades. Para compreender precisamente a situação problema, por exemplo, fizeram uso da capacidade analítica decorrente da extensa prática dos autores com ferramentas consultivas e, sobretudo, dos mais de 10 anos de experiência no setor siderúrgico de um dos autores. A compreensão do arcabouço teórico sobre processo estratégico era necessária porque o caso se manifestou como um desenrolar complexo de ações, discursos, documentos etc. Assim, o entendimento profundo tanto das teorias clássicas quanto das não clássicas de formação de estratégias permitiu se enxergar além do trivial e identificar o papel da criação de sentido e do processo incremental, como se verá no decorrer desse artigo. Este último requisito foi cumprido por um dos autores o qual teceu tese de doutoramento sobre o tema "processo da estratégia" e gerou a redação final desse artigo.

\section{MARCO TEÓRICO}

Uma questão importante em teoria organizacional é sobre como se formam as estratégias empresariais. Há diversas escolas neste tocante, de um lado, encontra-se a visão extremada de que novas estratégias provém de experimentações aleatórias. Neste sentido, autores, tais como Hannan e Freeman (1997), apontaram para a tradição intelectual da "ecologia de organizações" a qual indica que as estratégias surgem a partir de movimentos ambientais. Tais autores afirmam que o ambiente de uma empresa é implacável e imprevisível para que se façam previsões. Mintzberg e Waters (1985) assinalam que as estratégias se originam de modo emergente e adaptativo ao longo das decisões executivas. No outro extremo, encontra-se a visão de que as estratégias surgem a partir de análises cuidadosas e racionais das posições competitivas (Ansoff, 1965).

Em uma perspectiva prática, contudo, nenhuma de tais proposições parece satisfazer completamente os executivos. De um lado, experimentações aleatórias ou emergentes deixam pouco espaço para a gestão. De outro, os minuciosos planejamentos podem ser impraticáveis para muitas das circunstâncias mais dinâmicas de negócios e enfatizam, em demasia, o lado formal da formação de estratégias (Mintzberg, 2004). Tal relativa carência de instrumental satisfatório, é o que motivou, aparentemente, o vasto volume de modelos sobre como formular estratégias bemsucedidas que pudessem originar estratégias inovadoras. A este respeito, um quadro de referência que particularmente ressoou entre os gerentes é aquele denominado Estratégia do Oceano Azul (Kim \& Mauborgne, 2005). Tal arcabouço conceitual propõe a geração de estratégias por meio de um processo criativo em que se procura espaços de mercado inexplorados (oceanos azuis). Advoga que, por meio de tal inventividade, gerar-se-ia maior lucro econômico à empresa (Gorrell, 2005). Contrariamente, os "oceanos vermelhos" seriam aqueles mercados já existentes e que, em razão da competição acirrada, gerariam lucros estrangulados.

Kim e Mauborgne (2005) objetivam originar estratégias que superem a competição. Trata-se de um arcabouço conceitual que visa - mesmo que de modo não completo - superar a clássica visão da estrutura competitiva do setor como condutora da rentabilidade das companhias. Tanto que as teorias de Porter, como a EOA, enfatizam a premência de se evitar a concorrência. Alguns de seus pressupostos, contudo, são diversos. No âmbito da estratégia competitiva, percebe-se a preponderância na academia de que a prevenção à concorrência se fundamenta nos recursos da empresa (Penrose, 1959). De acordo com tal perspectiva, a posse de recursos únicos e difíceis de imitar cria uma vantagem competitiva sustentável e aumenta os lucros. Ao longo do tempo, contudo, outras empresas replicam o que já foi um recurso único, número de rivais aumenta e os lucros reduzem. Consistente com tais observações, Teece et al. (1997) destacam a importância das chamadas "capacidades dinâmicas" para criar continuamente recursos que gerem novas vantagens sustentáveis. Com isto em mente, não obstante, McEvily e Chakravarthy (2002) indicam a propensão das próprias capacidades dinâmicas de serem também replicadas. Dito de outro modo: de acordo com as perspectivas mainstream da estratégia, a inovação proporciona apenas resultados no curto prazo.

Em contraposição, os defensores da EOA advogam uma visão mais otimista do impacto da inovação sobre a rentabilidade da empresa. Segundo eles, se existem barreiras à imitação e se as empresas encontram mercados não explorados - ou criam nova demanda - por meio da inovação, então a principal preocupação estratégica das empresas não deve ser gerir a concorrência, mas, sim, inovar (Burke, Van Stel e Thurik, 2008). Para se desvencilhar da tradicional competição com os rivais - e da clássica dicotomia entre estratégicas de custo ou diferenciação -, Kim e Mauborgne (2005) apresentam uma abordagem cujo principal objetivo é levar a empresa para um "oceano" ainda inexplorado (ao que denominam "oceano azul").

O ponto chave para a criação de oceanos azuis é, segundo os idealizadores da teoria, a inovação de valor. Nesse aspecto, dar o enfoque apenas na criação de valor, sem inovação, tratar-se-ia de um aumento apenas incremental dos benefícios aos clientes; elemento insuficiente para que a empresa se distancie dos demais concorrentes e se sobressaia no mercado. Já a inovação sem valor seria motivada pela própria tecnologia em si, mas que não necessariamente implica que os clientes a desejam ou que estejam dispostos a pagar por ela de modo intenso. Com isso, é possível 
romper o dogma do trade-off valor-custo, em que se acredita que só é possível oferecer mais valor a custos mais altos ou mantendo-se o mesmo valor a custos menores (Kim e Mauborgne, 2005). Segundo a EOA, se a empresa se posicionar, em uma "curva de valor", de modo a ocupar espaços mais livres, ela poderá gerar tais resultados.

\section{CONTEXTO E SITUAÇÃO-PROBLEMA}

O contexto no qual se insere este trabalho é aquele do setor siderúrgico entre os anos de 2012 e 2013. Este ramo tem sido importante para a economia nacional. O Brasil era, em 2012, o nono maior produtor de aço do mundo e, no contexto da economia nacional, responsável por, aproximadamente, $4 \%$ do PIB. A siderurgia brasileira empregava, à época, mais de 120 mil pessoas. O parque industrial era formado por 29 usinas com faturamento bruto de cerca de US\$ 35 bilhões (Instituto Aço Brasil, 2012).

Tal setor sofreu, no período analisado, contudo, uma queda do preço do aço e incrementos na cotação do minério de ferro, principal matéria-prima utilizada. Isso fez com que as siderúrgicas trabalhassem com margens menores. Veja Figura 1.

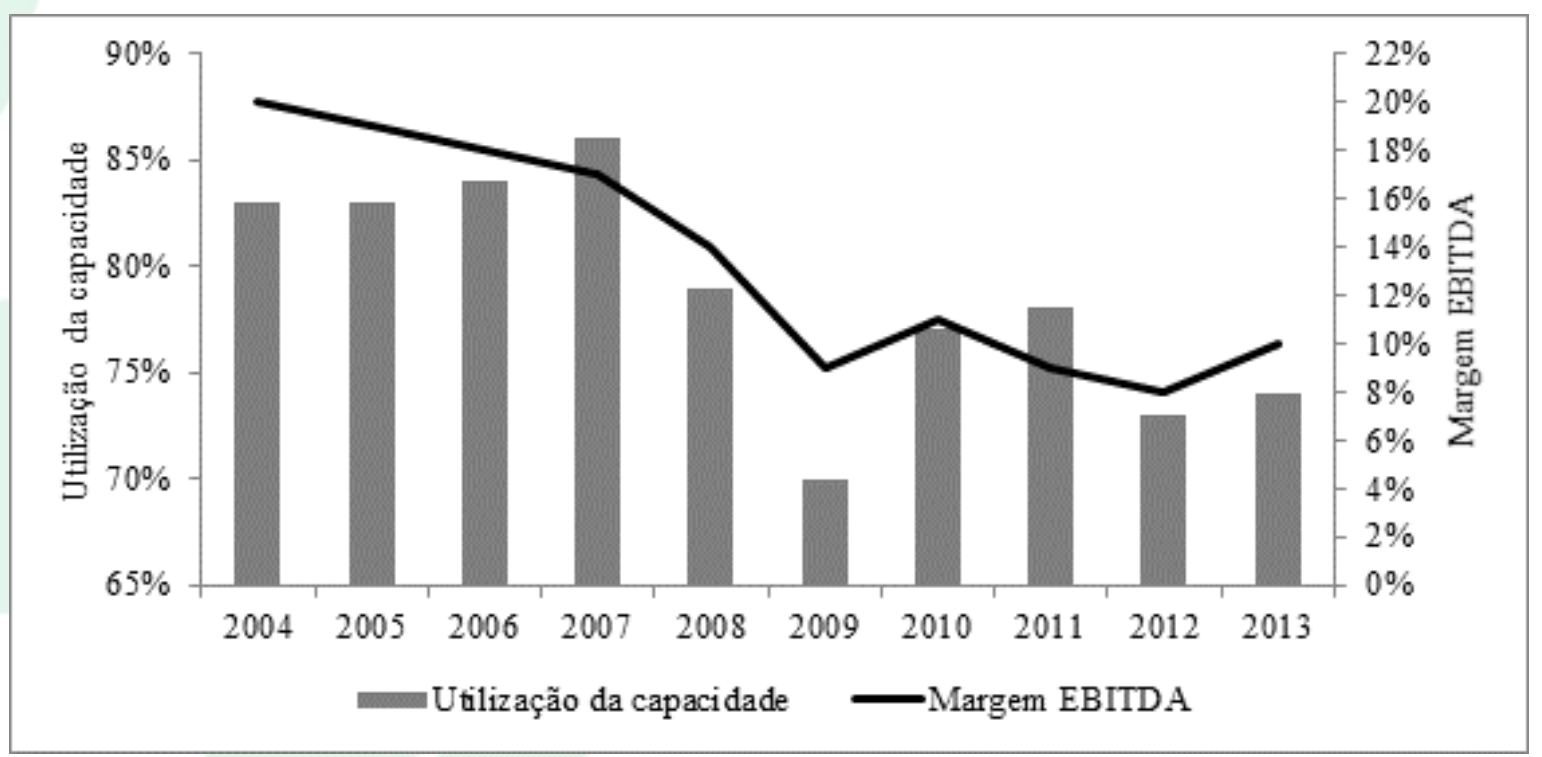

Figura 1 - Relação entre utilização da capacidade e margem Ebitda no setor siderúrgico brasileiro

Fonte: World Steel Association (2013)

A empresa Alfa viu suas margens de contribuição ser achatadas do mesmo modo que as demais firmas siderúrgicas. Assim, sua margem Ebitda saiu de, aproximadamente, 90\% em 2004 para cerca de $15 \%$ em 2013. Outros elementos complementam o cenário vivido no período anterior à intervenção da EOA. Entre 2006 e 2012, a exportação de aço brasileiro caiu praticamente à metade, apesar de ainda impactar positivamente a balança comercial em US $\$ 1,3$ bilhão, sendo o $17^{\circ}$ maior exportador mundial de aço e o sexto maior exportador líquido de aço (Instituto Aço Brasil, 2012).

A empresa Alfa sofria, em 2012, exatamente este cenário. A empresa era uma das líderes do mercado de aços, tinha capital nacional e empregava, à época, mais de 10 mil pessoas. Como empresa de grande porte e atuante em um setor cujas inovações são enfocadas em ganhos de eficiência, a EOA parecia representar uma modificação significativa. Sendo uma empresa com destaque em exportação, a situação do mercado internacional a afetava sobremaneira.

Neste âmbito, a competição internacional se acirrou com a indústria siderúrgica da China. Aquele país implementou uma política de uso intensivo da capacidade de produção de seu grande parque fabril, ao mesmo tempo em que sua economia desacelerou. Com isso, a indústria siderúrgica chinesa respondeu por cerca de $50 \%$ da produção mundial em 2013, enquanto o setor se retraia em muitos países do mundo (Ribeiro, 2013). Como consequência, as importações indiretas de aço no Brasil cresceram, entre 2002 e 2012, mais de quatro vezes (Instituto Aço Brasil, 2012) e as usinas chinesas fecharam, em 2013, com o recorde de, aproximadamente, 800 milhões de toneladas produzidas - crescimento de $8 \%$ em relação a 2012 (Ribeiro, 2013).

Como a demanda mundial não acompanhou a ampliação fabril, formou-se uma capacidade excedente estimada em mais de 450 mil toneladas anual. Somente 
a China era responsável por mais de $65 \%$ deste volume; seguida pela Índia, com 9,7\%. A Turquia representou 3\% e o Brasil, 1,7\% (WordSteel Association, 2013). Diante deste cenário, além de atender sua demanda interna, as siderúrgicas chinesas foram agressivas em exportações. Em 2012, a ocupação média da capacidade das siderúrgicas ficou em torno de $74 \%$, fazendo com que os grandes produtores buscassem novos mercados para reduzir os custos gerados pelo seu excesso de capacidade. Havia, como típico do setor siderúrgico, altas barreiras de saída. Tais barreiras, conforme Besanko, Dranove, Shanley e Schaefer (2010), provocam altas taxas de rivalidade.

A Turquia, outro país relevante no cenário siderúrgico, também teve sua utilização da capacidade de produção de aço reduzida de $75 \%$ em 2012 para $70 \%$ em 2013. A explicação para a queda da utilização esteve na baixa taxa de crescimento da economia turca, que saiu de 8,8\% em 2011 para 2,2\% em 2012, e apresentou leve recuperação em 2013, com 4\% (em crescimento do PIB) (Turkish Steel Producers Association, 2012).

Como a empresa Alfa deveria competir diante deste contexto? Classicamente, se compreende que os lucros de uma firma dependem da lucratividade média geral do setor em que compete (Dranove \& Marciano, 2005). A priori, por se tratar de uma commodity, a maioria dos players acreditava que seria impossível competir a não ser em preço, o que levava ao entendimento que a estratégia genérica de menor custo (Porter, 1989) seria a única aplicável. Na situação da empresa aqui estudada, isso significaria continuar a navegar - na nomenclatura da EOA - pelos oceanos vermelhos já conhecidos. Àquela altura, todavia, ganhos de eficiência já eram muito mais difíceis porque a empresa já havia trabalhado tais alternativas e enxergava estar no limite das reduções de custos.

\section{ANÁLISE DA INTERVENÇÃO ADOTADA}

Este item apresenta o modo por meio do qual foi desenvolvido o conteúdo da nova estratégia de uma das unidades de negócios da empresa Alfa. Em síntese, a intervenção foi empreendida por meio dos seguintes alicerces: (i) Formação de equipe heterogênea; (ii) Não contratação de consultorias, em razão, sobretudo, do necessário sigilo; (iii) Coleta de insights, por meio de entrevistas com vários públicos; (iv) Processo estruturado de validação de ideias e (v) Utilização de focus group em diversas fases do processo. O objetivo, ao final, seria a construção de uma nova curva de valor. Tal curva de valor deveria alterar os movimentos da empresa com certa radicalidade e proporcionar significativa melhoria na relação da empresa com clientes. A participação de um dos autores foi bastante intensa. Ele atuou na equipe gerencial do projeto e pôde observar, tanto ao longo do projeto em si quanto no momento da construção deste artigo, as nuances da implementação de uma metodologia complexa de geração de estratégias.

\subsection{Macroetapas}

O processo de construção da curva foi empreendido durante três meses e se deu segundo as etapas da Figura 2. Uma curva de valor é um gráfico representativo que permite visualizar a desempenho da empresa nos fatores-chaves do setor (Kim \& Mauborgne, 2005). Inicialmente, formou-se o time que levaria a cabo as iniciativas. Como exposto posteriormente, a construção do melhor time estava entre as principais preocupações. Uma das razões para tal inquietação refere-se ao fato de que não se contratou consultorias. Ainda na primeira fase, empreendeu-se uma revisão teórica em que três membros do futuro time estudaram a literatura e desenvolveram um seminário educacional. Uma segunda fase envolveu a análise dos dados secundários oriundos, principalmente, dos estudos de contentamento de clientes. Tal ênfase se deu em razão da hipótese de que a nova estratégia deveria satisfazer os clientes e não ganhos de eficiência.

A curva de valor foi construída de modo incremental. Esta foi uma das características interessantes do projeto. Entre a segunda e terceira fase, como ilustrado na Figura 2, desenvolveu-se a primeira versão das curvas de valor. Tais versões preliminares foram elaboradas a partir das visões dos principais executivos. Em certo sentido, portanto, todas as demais fases serviriam para incrementar e testar o primeiro rascunho. Tanto a Curva de Valor Corrente (CVC) quanto a futura (CVF) foram desenhadas de modo incremental. Tal aspecto parece ir ao encontro dos achados de Mintzberg (1978), ao indicar que as estratégias são formadas por meio de "padrões" que vão se consolidando ao longo do tempo. No caso estudado, os executivos e o "sistema de crenças" (Eden, 1993) da empresa já apontava genericamente para onde a empresa deveria caminhar. O projeto ora debatido, portanto, pode ser, em parte, interpretado como um conjunto de ações de detecção de tais pressupostos, criação de sentido entre executivos e gerentes (sensemaking) (Weick, 1995) e formalização da estratégia por meio da construção da CVF. Entendese "criação de sentido" como "[...]o processo interpretativo necessário para que os membros da organização entendam e compartilhem o seu entendimento acerca dos mais diversos temas em uma organização" (Russo, Frederick \& Nogueira, 2008, p. 27).

A figura 2 descreve as etapas do projeto. $\mathrm{O}$ trabalho iniciou-se com revisão da teoria e dos dados internos. Com base em tal etapa, que durou aproximadamente duas semanas, construiu-se os roteiros de entrevistas. Os roteiros foram elaborados com base nos diversos atributos existentes nas pesquisas de satisfação. Como se percebe, o projeto EOA da empresa Alfa tinha foco em compreender as 
Estratégia do Oceano Azul: Relato de Implantação em um Setor em Crise

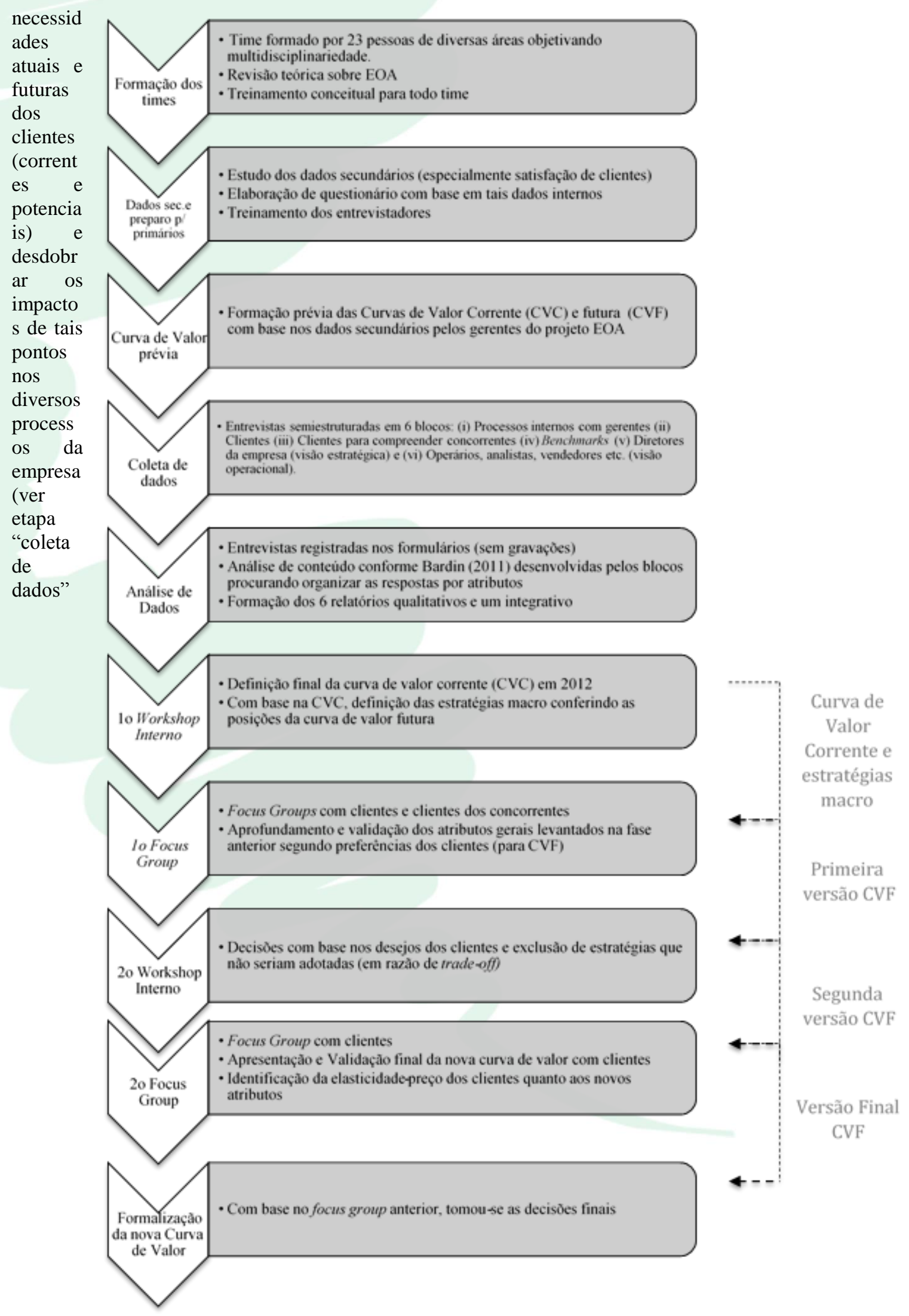

da

figura

2). Nas

entrevist

as para a

construç

ão desse

relato,

evidenci

ou-se

que

havia a

necessid

ade de

se

desenvo

lver

estratégi

as "de

fora

para

dentro".

Curva de

Valor

Corrente e

stratégias

macro

Primeira

versão CVF

Segunda

versão $\mathrm{CVE}$

Versão Final

CVF 
Figura 2 - Processo macro de desenvolvimento da curva com suas explicações centrais Fonte: Autores (2015)

Uma das primeiras etapas indicadas, na figura 2, foi a construção prévia das curvas de valor atual e futura. Fez-se isso tal como "uma hipótese a ser detalhada e trabalhada", segundo as palavras de um dos líderes do projeto. Tal construção prévia foi entendida como fator-chave para o sucesso. Assim, "[...]todos puderam ter uma visão do resultado final desde o início (...) (o que) gerou maior engajamento e motivação", de acordo com o mesmo executivo.

Embora tal edificação preliminar das curvas de valor tenha sido interpretada como fator facilitador, as entrevistas indicaram o receio de demasiada ancoragem reduzindo, assim, o potencial criativo. A ancoragem ocorre quando indivíduos, no processo decisório, usam uma referência (âncora) para eleger uma certa orientação de ação (Tversky \& Kahneman, 1974). Tal temor, contudo, pareceu menor, haja vista que as curvas de valor prévias foram validadas por meio do processo ilustrado na figura 2. A atenção ao risco de ancoragem, mesmo assim, pode ser entendida como fator de atenção.

Assim, muito embora existisse tal hipótese preliminar para as curvas de valor, o pressuposto discorrido pela maioria dos executivos entrevistados era a de que seria necessário obter-se visões não ortodoxas. A EOA, assim, configurou-se como uma possível maneira para se sobrepujar aos desafios indicados em itens anteriores (análise do contexto). Isto porque tal teoria era entendida como contributiva para a necessidade de se "pensar fora da caixa" - expressão frequentemente utilizada pelos executivos da Alfa.

Após o desenho das curvas de valor preliminares, a equipe passou a desenvolver um extenso conjunto de entrevistas. Nas palavras de um executivo "[...] somente a variedade das fontes ofertaria transformação às decisões e ações". Como detalhado posteriormente, foram entrevistados gerentes internos, clientes atuais, compradores que então adquiriam produtos dos concorrentes, empresas de outros ramos (consideradas "benchmarks"), todos os diretores da unidade e, também, profissionais de nível operacional. A escolha por entrevistar também o "chão de fábrica" foi particularmente enriquecedora. Um entrevistado indicou objetivamente um ou dois elementos que foram modificados na curva de valor futura, em decorrência de opiniões manifestadas por colaboradores dos níveis hierárquicos inferiores.

Posteriormente, às entrevistas, empreendeu-se a análise de conteúdo que gerou sete relatórios. Tal metodologia avaliou os resultados das entrevistas partindo de uma perspectiva quantitativa, avaliando numericamente a frequência de ocorrência de termos (Bardin, 2011). Fora necessária tal inclusão metodológica porque o volume de entrevistas era considerado elevado. A perspectiva quantitativa também facilitou a conversação sobre a estratégia, uma vez que a maioria dos profissionais envolvidos era formada por engenheiros, que tendiam a pensar mais acuradamente quando expostos a dados quantitativos. Por outro lado, coletou-se o testemunho de que a análise de conteúdo tenha tomado "muito tempo".

Com os relatórios em mãos, empreendeu-se uma série de workshops. A escolha pelos workshops (públicos internos) e focus group (públicos exteriores) representou uma preferência que geraria sensemaking e permitiria a geração de ideias criativas. Tal escolha vai ao encontro da literatura. Para Liamputtong (2011), o grupo de foco é uma técnica social de coleta de dados 
que facilita - por meio da interação entre indivíduos - a geração de ideias.

No projeto em estudo, tais discussões ocorreram em quatro momentos: (i) Um primeiro, workshop interno que visou a elaborar a CVC, mas que já levantou insights para as estratégias futuras; (ii) Um focus group, objetivando aprofundar e convalidar com clientes importantes os atributos gerais da curva; (iii) Um segundo debate interno - mais profundo e detalhado - em que se escolheu a nova curva de valor (CVF) e se excluiu certas requisições dos clientes que gerariam trade-offs demasiados e (iv) um último grupo de foco com clientes para legitimar a nova curva. Contudo, posteriormente, se modificou a CVF pois, neste mesmo último focus group, se estimou os preços que os clientes se predisporiam a pagar por maior nível de serviço (estimativa da elasticidade-preço). Em certos casos, se extraiu da CVF efetiva itens não economicamente viáveis (última etapa da figura 2). Tal convalidação foi desenvolvida, como indicado no item 4.2, por um comitê particularmente indicado para os refinamentos da CVF.

Tais etapas sintetizam o trabalho empreendido. Para levar adiante tal alteração nas estratégias competitivas, contudo, o entendimento praticamente homogêneo entre os dirigentes era de que seria necessária uma modificação "[...]no modo por meio do qual formulamos nossas estratégias", disse um diretor. A ênfase se daria, assim, em processos mais criativos, participativos e que privilegiassem ideias "do lado do cliente". A explicação subsequente relata como a empresa desenvolveu sua curva de valor.

\subsection{Equipe de trabalho}

A questão das pessoas envolvidas no projeto de análises e na concepção da nova curva de valor foi considerada essencial. Os profissionais envolvidos no processo de planejamento, entrevistas, grupos focais e construção da curva de valor foram organizados em uma estrutura organizacional paralela à principal. Foi criada uma estrutura de projeto para viabilizar tal feito, sendo sua maior posição a de "Gerente de Projeto", ocupada por um executivo de alta gerência. Este já foi um importante fator facilitador: o poder político, a credibilidade e o carisma do gerente geral do projeto EOA facilitaram o andamento correto do cronograma andasse e possibilitou que todos se engajassem na iniciativa.

Por se tratar de um projeto com diversas ações com impactos em diferentes áreas da organização, organizaram-se "frentes de trabalho". Tais frentes de trabalho podem ser caracterizadas como subprojetos dentro de um projeto maior. Para cada subprojeto - ao todo foram criados seis - foi designado um líder responsável pelos entregáveis, prazo, custo e gestão de pessoas. Os ocupantes desta posição tinham características pessoais de liderança e não necessariamente ocupavam, todavia, posições de direção na estrutura organizacional contínua. Eles foram escolhidos porque exerciam influência sobre os demais e tinham suas atividades de rotina relacionadas à frente de trabalho. Para esta posição, foram selecionados gerentes de área, coordenadores e assessores que, embora tivessem níveis hierárquicos distintos na organização, eram equiparados na estrutura do projeto EOA. Um dos executivos da empresa considerou este item como fator crítico por "incorporar um elemento de motivação". Vale ressaltar que tal amplitude de experiências e níveis hierárquicos possui alicerce na literatura sobre estratégia empresarial. Para Bower e Gilbert (2007, p. 9), por exemplo, “[...]o conhecimento requerido para as decisões estratégicas estão dispersos nos diversos níveis e através da organização[...]" e, ainda, "[...]gerentes com diferentes perspectivas contribuem para o processo decisório estratégico" (idem, p. 9).

Um grupo formado por especialistas no negócio deu origem ao chamado "Comitê de Coordenação", cuja responsabilidade foi dar os direcionamentos aos coordenadores. Existia ainda o "Comitê de Validação", formado pelos principais executivos da empresa, entre eles diretores e vice-presidente. A função deste último comitê foi aprovar as soluções propostas pela equipe para buscar a inovação de valor propugnada por Kim e Mauborgne (2005). Tal grupo trabalhou na última fase. Diante do desafio de se implementar a EOA, a empresa optou por não usar nenhum recurso humano externo à empresa, mesmo que tal decisão implicasse em mais tempo despendido com pesquisas acerca dos conceitos teóricos. Não se podia desprezar o custo financeiro envolvido na contratação de uma consultoria, mas a principal razão para tal julgamento foi garantir a confidencialidade do projeto. Aqui se relata uma especificidade interessante deste relato técnico, pois muito frequentemente consultorias internacionais seriam acionadas.

A equipe foi formada por 23 pessoas. A heterogeneidade das áreas de atuação de cada membro, tais como Logística, Marketing, Engenharia etc., contribuiu para que cada etapa do projeto pudesse ser analisada de diferentes perspectivas. Tal multiplicidade de pontos de vistas foi considerada como um dos principais pontos de aprendizagem. "Se houvéssemos optado por um time 'clássico', estou certo que não teríamos as soluções que engendramos”, disse um diretor.

\subsection{Coleta e organização de informações}

Uma vez formada a equipe, iniciou-se a coleta de informações. Ao final, contabilizou-se, aproximadamente, 540 entrevistas com os mais diversos públicos. De posse das informações preliminares oriundas dos sistemas internos e pesquisas, já era possível identificar algumas tendências de comportamento dos clientes, bem como algumas oportunidades identificadas, tal como a possibilidade de oferta dos mesmos produtos com maior valor agregado. 
As oportunidades que deveriam continuar sendo exploradas foram mais debatidas em grupos focais, tornando-as cada vez mais tangíveis. Um problema que se percebeu é que os workshops e as entrevistas com clientes ofertavam apenas as noções mais abstratas. Neste ponto, foram envolvidos os principais gestores dos processos funcionais para analisar taticamente sobre como converter as oportunidades identificadas em ganhos concretos.

O objetivo final, conforme indica a última etapa da Figura 2, era a construção da curva de valor. Interessantemente, a preferência foi por uma construção contínua da curva. Isto é, mesmo que a figura 2 indique que se objetivava sua construção final apenas com a consumação do processo, optou-se por construí-la de modo incremental. A versão primitiva da curva de valor surgiu no primeiro workshop e foi sendo lapidada nas demais etapas. Tal processo incremental vai ao encontro de algumas das principais teorias sobre geração de "ideias estratégicas" (Roos, 2006). De acordo com tais perspectivas, a origem das estratégias disruptivas tende a estar relacionada com mecanismos menos formais e contínuos de reflexão.

Para a construção da curva de valor - mais propriamente na definição dos atributos pelos quais as empresas são comparadas pelos clientes - e avaliar a aderência de cada empresa a cada um dos atributos, acreditava-se ser fundamental ir a campo e ouvir todas as partes interessadas. A multiplicidade de fontes de informação e heterogeneidade das visões era considerada essencial. De certo modo, esta etapa pode ser considerada a mais crítica, pois demandou muito esforço.

Os clientes seriam a fonte preponderante de informações. $\mathrm{O}$ primeiro passo foi identificar os principais processos de atendimento ao cliente, desde seu primeiro contato com a empresa até o recebimento do produto, para que se pudesse avaliar a satisfação dos compradores em relação a cada um dos processos. Para que as informações coletadas fossem relevantes, seria preciso que o público entrevistado tivesse conhecimento suficiente para avaliar o processo, de maneira justa. Um comprador, por exemplo, não poderia avaliar com precisão a qualidade do serviço de entrega, mas sua avaliação acerca do processo de vendas da empresa seria mais rica. Havia, então, diferentes instrumentos de coleta de dados para os diferentes públicos.

Inclusive, neste sentido, em busca de maior representatividade para a criação da curva de valor, a empresa optou por entrevistar, além do público comprador principal, seis outros públicos diferentes: responsável pelo departamento de suprimentos, técnicos responsáveis pela especificação e detalhamento dos serviços oferecidos, almoxarifes responsáveis pelo recebimento, conferência, armazenagem e organização do produto no local de utilização - e gerência responsável pela operação que consome o aço, além de dois outros públicos técnicos especialistas na utilização do produto e processo produtivo do cliente.

Por se tratar de um projeto em âmbito nacional, que, de certo modo, traria uma padronização do produto oferecido aos clientes, foram selecionados clientes dos principais polos consumidores nas cinco regiões brasileiras. Essa abordagem permitiu identificar certos traços regionais e diferentes percepções. Enquanto a região de São Paulo, por exemplo, priorizava pontualidade na entrega, esta apareceu apenas na quinta posição em Recife.

\subsubsection{Preparação das entrevistas e entrevistadores}

Os entrevistadores escolhidos eram oriundos da própria equipe do projeto. Além da confidencialidade já apresentada, a opção por pessoas internas visou a garantir que entrevistadores seriam conhecedores do processo. Um entrevistador também poderia se deparar com outras oportunidades não esperadas pelo protocolo de coleta. Outro benefício indireto foi a aproximação da empresa com o cliente. $\mathrm{O}$ fato de lidar face a face gerou um impacto muito maior, sentimento de responsabilidade e de compromisso com o cliente.

As entrevistas foram realizadas em duplas, sendo uma pessoa ligada diretamente ao processo (por exemplo, um gerente de vendas entrevistando um comprador do cliente) e outra de outra especialidade. Isto gerou duas óticas distintas que posteriormente, no relato de cada entrevista, foram consideradas. Foi utilizado um questionário semiestruturado, com perguntas elaboradas de forma que não influenciassem a resposta do entrevistado.

As entrevistas não foram restritas aos clientes, mas também os não-clientes, isto é, aqueles que compravam o mesmo produto dos concorrentes. Dessa forma, foi possível captar suas percepções sobre os serviços e produtos oferecidos pelos rivais. Esta "inteligência competitiva" era vital para a construção mais precisa da curva de valor. Foram entrevistadas pessoas diretamente ligadas à operação, tais como os operadores, técnicos e motoristas, que contribuíram com suas percepções. Referências externas, como outras empresas reconhecidas por serem benchmarks em algum tipo de processo semelhante, foram também estudadas e entrevistadas; foram 25 empresas neste quesito. Veja Figura 3. 


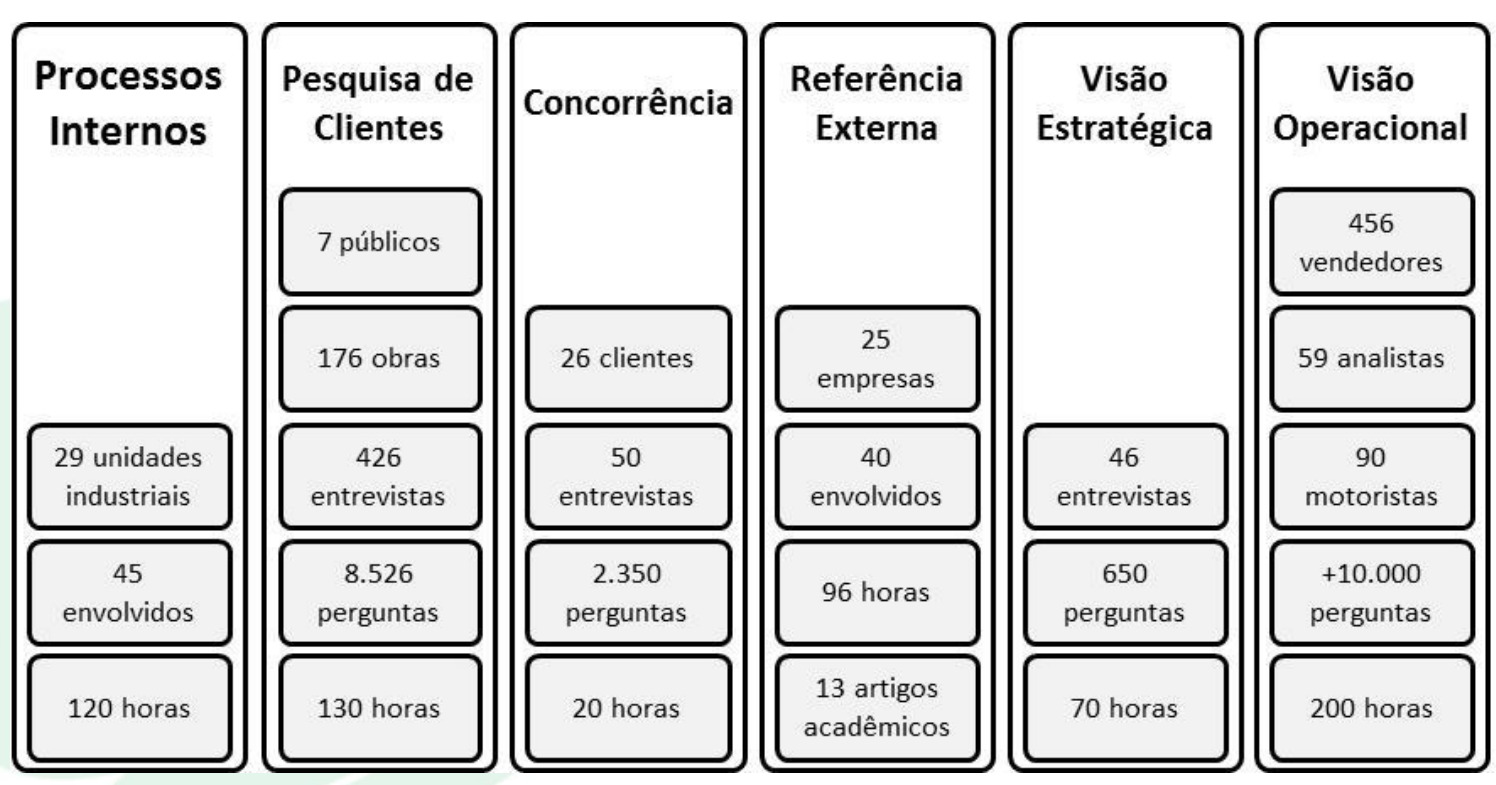

Figura 3 - Fontes de informação para construção da curva de valor Fonte: Os autores, baseados em documento da empresa Alfa

\subsubsection{Focus Groups e Workshops}

Para aprofundar os atributos coletados na fase de entrevistas, realizou-se grupos focais os quais, inclusive, permitiram que a equipe se entranhasse nas questões mais chave e, também, que avaliasse a confiabilidade das informações obtidas. $\mathrm{O}$ anonimato do patrocinador do focus group permitiu que os participantes não se deixassem influenciar por suas experiências ou relacionamentos com a empresa. Ao contrário das demais fases do projeto, neste momento, contratou-se um instituto de pesquisa e salas especialmente desenvolvidas para as discussões.

$\mathrm{Na}$ primeira rodada de focus group, o objetivo era validar os atributos futuramente partícipes da curva de valor. Após validação e surgimento de propostas para criar uma nova curva de valor, houve outra rodada de discussões em grupo, mas dessa vez a intenção foi verificar a viabilidade das mesmas. Após confirmar se o cliente realmente estaria interessado por um 
incremento em um atributo, era preciso saber o quanto estaria disposto a pagar a mais por aquele incremento. Em alguns casos, os participantes afirmaram que pagariam até $20 \%$ mais pelo produto caso se apresentasse uma melhora considerável.

Após a identificação dos pontos em comum levantados pelos entrevistados, foram necessárias várias tentativas para consolidá-los, de forma a transformá-los em atributos para comparação. Já pensando na curva de valor que seria construída em seguida, os atributos foram direcionados para facilitar sua construção, o que pode ter induzido os atributos identificados. Percebeu-se que a maneira como um atributo era escrito influenciava diretamente a matriz elevar-reduzir-elevar-criar de Kim e Mauborgne (2005). Um certo atributo, escrito de uma maneira, poderia ser colocado no quadrante "elevar" da matriz. Todavia, o mesmo atributo, escrito de maneira diferente ou com o uso de adjetivo, poderia ser encaixado no quadrante "reduzir". Evitar tais vieses cognitivos. Este é um dos cuidados por se tomar ao se construir formulações estratégicas.

Talvez o ponto mais polêmico da elaboração da curva tenha sido a dosimetria. Como quantificar a posição da empresa em relação a cada atributo e, principalmente, em relação à concorrência? Não se identificou, na revisão teórica, uma metodologia clara que quantifique os dados das entrevistas. Caso a opinião dos entrevistadores fosse unânime, certamente a nota seria também aquela da unanimidade. As intensidades de cada atributo foram baseadas de acordo com a proporção em que apareceram nas entrevistas como crítica ou sugestão, sendo adequada a escala com a percepção dos entrevistadores. Neste sentido, aplicou-se uma análise de conteúdo quantificadora das expressões e indicações dos mais de mil entrevistados. Não se utilizou pacote de software para isso. Ao final, o comitê de validação atribuiu a nota final.

\subsection{Resultados da nova curva de valor}

O presente RT, por sigilo, não demonstra a nova curva de valor da empresa Alfa, não obstante, os autores não consideram tal ponto uma fraqueza do artigo. Isto porque o anseio foi descrever o processo de construção da estratégia. Contudo, para validar que o processo aqui descrito possui credibilidade, é necessário se descrever os resultados posteriormente à adoção da nova curva de valor. A empresa Alfa reconstruiu sua curva de valor de modo significativo, incorporando maior customização das entregas, aumentou o nível de serviços ao cliente e flexibilizou suas rotinas para atendimento de pedidos urgentes. Um conjunto bastante "fora da caixa" de soluções de engenharia foram engendrados a partir da construção da curva.

Em uma pesquisa bianual realizada pela empresa Alfa para avaliar a satisfação dos clientes, o resultado global foi 1,8 ponto percentual superior à pesquisa anterior à intervenção. Comentários qualitativos reforçaram o sucesso da iniciativa. Os fatos mais relevantes desta pesquisa foram a diminuição de reclamações sobre a confiabilidade das datas de entrega e muitos elogios às novas soluções de negócio implementadas. Qualitativamente perante clientes, portanto, a EOA gerou insights relevantes. Mesmo com um preço ligeiramente superior à média da concorrência, alguns clientes - principalmente os localizados nos grandes centros urbanos - optaram pela empresa Alfa por ser a única a oferecer um modelo de entrega que driblava os problemas enfrentados pelas restrições de acesso e circulação impostas naquele momento pelo poder público. Enfim, as palavras de um executivo evidenciam o sucesso da EOA no caso: "agora todos os colaboradores envolvidos com a estratégia têm grande comprometimento".

\section{CONCLUSÕES E CONTRIBUIÇÕES À PRÁTICA EMPRESARIAL}

$\mathrm{O}$ anseio principal deste relato técnico foi apresentar a implementação da EOA em uma empresa situada em uma indústria que enfrentava redução de margens de lucro devido ao processo competitivo. Visou-se, particularmente, a indicar os principais fatores facilitadores, bem como as dificuldades que surgem neste processo. Com tais informações em mãos, espera-se que outras empresas possam empreender diligências de geração de estratégias que utilizem este arcabouço teórico. O RT se justifica porque o setor estudado é relevante e, sobretudo, a implementação de EOA em ramos B2B "comoditizados" é considerada desafiadora. No âmbito acadêmico, em adição, segundo Hong, Chai e Wan Ismail (2011, p.86), “a Estratégia do Oceano Azul é um dos temas em Estratégia que mais merecem estudos adicionais".

Como expresso no trabalho, destaca-se que as entrevistas foram cruciais para chegar ao resultado obtido. O tamanho da amostra e a diversidade do público escolhido contribuíram para que as entrevistas fossem representativas. A construção criativa da curva de valor foi possível pelo uso de grupos focais, em que se pôde testar hipóteses e debater com detalhes as soluções propostas. Outro fator importante foi a preparação dos entrevistadores para que pudessem capturar nuances acerca das percepções dos públicos até então desconhecidos. A combinação de entrevistas realizadas em duplas, sendo uma delas profunda conhecedora do processo em que se está entrevistando, e outra leiga, também estimulou respostas com riqueza nos detalhes.

Por outro lado, quanto maior o tamanho da amostra maior a quantidade de trabalho e despesas. Incidiu-se importantes custos para realizar as entrevistas e grupos focais em diversas regiões, além de ser um processo demorado. Muitas empresas podem não investir os recursos necessários nesta importante 
fase de coleta de dados por questões financeiras ou de tempo.

Este estudo demonstrou também importância da geração de sentido compartilhado quando da formação de estratégias. Muitas das entrevistas denotaram tal fato. Além dos resultados em si, o processo estratégico relatado logrou um significativo senso de compartilhamento de uma mesma visão dos desafios empresariais da empresa Alfa. A construção da curva pelo grupo de 23 colaboradores gerou tal "sensemaking". O processo de sensemaking, conforme analisado por Correa, Rese, Sander e Ferreira (2014), busca tornar as mudanças organizacionais conhecidas e internalizadas mediante um framework de significados partilhados pelos colaboradores. A tabela 1 sintetiza este e outros achados.

Tabela 1 - Principais facilitadores e dificultadores ao se implementar a EOA

\begin{tabular}{|c|c|}
\hline PRINCIPAIS FACILITADORES & PRINCIPAIS DIFICULTADORES \\
\hline $\begin{array}{l}\text { Entrevistas e trabalhos em grupo realizados pela própria } \\
\text { equipe responsável pela implementação posterior da } \\
\text { estratégia. Isto gerou comprometimento e garantiu } \\
\text { sigilo. }\end{array}$ & $\begin{array}{l}\text { Subjetividade na definição dos atributos e } \\
\text { na dosimetria necessária à construção da } \\
\text { curva de valor. }\end{array}$ \\
\hline $\begin{array}{l}\text { Opção por coletar informações primárias de modo } \\
\text { exaustivo e multidisciplinar. Tal heterogeneidade de } \\
\text { fontes engendrou as múltiplas visões que levariam à } \\
\text { nova curva de valor (CVF) }\end{array}$ & $\begin{array}{l}\text { Custo elevado para realizar as entrevistas } \\
\text { em grande escala e abrangência. } \\
\text { Igualmente, tempo bastante extenso para } \\
\text { todo processo (ver figura 2) }\end{array}$ \\
\hline $\begin{array}{l}\text { Preparação dos entrevistadores para condução e } \\
\text { aproveitamento das entrevistas e aplicação de duplas de } \\
\text { entrevistadores }\end{array}$ & $\begin{array}{l}\text { Exposição, possivelmente, precoce, aos } \\
\text { clientes, de } \\
\text { que noluções e níveis de } \\
\text { quarviço } \\
\text { implantados }\end{array}$ \\
\hline $\begin{array}{l}\text { Construção da curva, por meio de um método } \\
\text { incremental, a partir de uma primeira curva de valor } \\
\text { considerada como hipótese. Tal ponto originou } \\
\text { praticidade e, ao mesmo tempo, também permitiu o } \\
\text { sensemaking. }\end{array}$ & $\begin{array}{l}\text { Ausência de conhecimento teórico e } \\
\text { prático anterior gerou "idas e vindas" que } \\
\text { poderiam ser evitadas }\end{array}$ \\
\hline $\begin{array}{l}\text { Existência de etapas e mecanismos enfocados na } \\
\text { geração de ideias e outros para sua convalidação. } \\
\text { Adoção de métodos estruturados de debate em grupo tais } \\
\text { como focus groups. } \\
\text { Exploração de fontes de informação não tipicamente } \\
\text { adotadas na formulação de estratégias, tais como } \\
\text { benchmarks e não-clientes } \\
\text { Uso de análise de conteúdo para permitir melhor } \\
\text { quantificação e racionalizar a interpretação das } \\
\text { entrevistas }\end{array}$ & $\begin{array}{l}\text { As construções, a priori, da CVC e CVF } \\
\text { podem ter gerado excessiva ancoragem no } \\
\text { processo decisório }\end{array}$ \\
\hline
\end{tabular}

Fonte: Os autores (2015)

A tabela 1 resume os resultados do trabalho e responde à pergunta "Que métodos e etapas podem ser considerados bem-sucedidos ao se levar a cabo formulações estratégicas com base no arcabouço da EOA?" Este relato técnico gerou tal fruto com base no caso de uma empresa de grande porte do setor siderúrgico. Esse artigo possui os limites oriundos desta escolha. Em outros ramos e circunstâncias, os achados acima podem não ser prevalentes. Ainda quanto as ressalvas, entende-se que o relato explorado tenha especificidades que tornam a transferabilidade de seus achados relativamente limitada. Isto tende a ser atributo dos estudos baseados em casos (Eisenhart, 1989).
Por fim, os autores ofertam sugestões de estudos futuros. Tendo por base a discussão ora exposta, futuras pesquisas ou relatos podem aprofundar a questão da criação de sentido (sensemaking) em projetos de EOA, por meio de vivências etnográficas. Uma outra sugestão é a elaboração de um estudo de caso múltiplo que compare resultados, pressupostos, etapas etc. em conjunturas diferentes. Tal estudo de caso múltiplo geraria grande riqueza tanto prática quanto teórica.

\section{REFERÊNCIAS}


Ansoff, I. (1965) Corporate strategy. McGraw Hill, New York.

Bardin, L. (2011) Análise de conteúdo. Edições 70. Lisboa. Portugal.

Besanko, D., Dranove, D., Shanley, M. \& Schaefer, S. (2010) A economia da estratégia ( $5^{\mathrm{a}}$ Ed.). Porto Alegre: Bookman

Biancolino, C. A., Kniess, C. T,, Maccari, E. A., Rabechini Jr. (2012) Protocolo para elaboração de relatos de produção técnica. Revista de Gestão $e$ Projetos, 3(2), 294-307.

Bower, J.L. \& Gilbert, C. G. (2007) From resource allocation to strategy. Oxford University Press, Nova Iorque

Burke, A., Van Stel, A., Thurik, R. (2008) Blue ocean versus competitive strategy: theory and evidence. EIM Research Report Number H200801, Holanda.

Correa, M.V.P., Rese, N., J.A., Sander, J.A. \& Ferreira, J.A. (2014) O papel do sensemaking nos processos de mudança nas organizações. Anais do Encontro de Estudos Organizacionais. Associação Nacional de Pós-Graduação em Administração, 8, Gramado. Rio Grande do Sul, Brasil.

Dranove D. \& Marciano, S. (2005) Kellog on strategy: concepts, tools and frameworks for practitioners. Hoboken, New Jersey: John Wiley \& Sons.

Eden, C. (1993) From the playpen to the bombsite: the changing nature of management Science, Omega, $21,139-154$

Eisenhart, K.M (1989) Building theories from case study research. Academy of Management Review, 14(4), 532-550.

Gorrell, C. (2005) Quick takes. Strategy \& Leadership. 33, 64-70.

Greenwald, B. \& Kahn, J (2005) Competition demystified: a radically simplified approach to business strategy, Ed. Portifolio, Nova Iorque.

Hannan, M.T., Freeman, J. (1977) The population ecology of organizations. American Journal of Sociology, 82(5), 929-924.

Hong, A.N.H., Chai, D.L.J \& Wan Ismail, V.K. (2011) Blue ocean strategy: a preliminary literature review and research questions arising. Australian Journal of Basic and Applied Sciences, 5(7), 86-91.

Instituto Aço Brasil (2012) Relatório anual do setor de Siderurgia 2012, São Paulo, Brasil.
Instituto Aço Brasil (2015) Relatório anual do setor de Siderurgia 2015, São Paulo, Brasil.

Kim, W., \& Mauborgne, R (2005) A estratégia do Oceano Azul: como criar novos mercados e tornar a concorrência irrelevante. Rio de Janeiro: Elsevier.

Kim, W. \& Mauborgne, R. (2009) How to implement blue ocean strategy. Harvard Business School Case - Teaching Notes.

Liamputtong, P. (2011) Focus group methodology: principles and practice. Thousand Oaks, CA: Sage.

Mcevily, S.K. \& Chakravarthy, B. (2002) The persistence of knowledge-based advantage: an empirical test for product performance and technological knowledge. Strategic Management Journal, 23(4), 285-305.

Mintzberg, H. (2004) Ascensão e queda do planejamento estratégico. São Paulo: Bookman.

Mintzberg, H., (1978) Patterns in strategy formation. Management Science, 24(9), 934-38

Mintzberg, H, \& Waters, J. A. (1985) Of strategies, deliberate and emergent. Strategic Management Journal, 6, 257-272

Penrose, E. (1959) The theory of the growth of the firm, New York.

Porter, M. E. (1989) Vantagem competitiva. (1ª Ed.), Rio Janeiro, Editora Campus.

Ribeiro, I. (2013) China continua ditando o rumo na siderurgia. Jornal Valor Econômico, 6 de Janeiro, São Paulo, Brasil.

Roos, J. (2006) Thinking from within: a hands-on strategy practice. Nova Iorque: Palgrave Mcmillan.

Russo, R.F.S., Frederick, B.W.B. \& Nogueira, C.M. (2008) Criação de sentido e decisão naturalista. Gestão e Regionalidade, 24(72), 27-37, Set-Dez.

Teece, D., Pisano G. e Shuen, A. (1997) Dynamic capabilities and strategic management, Strategic Management Journal, 18(7).

Turkish Steel Producer Association (2012). Turkish Steel Industry in 2013 report. Recuperado em: 15 out.2015, de: http://www.dcud.org.tr/en/

Tversky, A. \& Kahnemann, D. (1974) Judgment under Uncertainty: Heuristics and Biases. Science, 185(4157), 1124-1131 
Weick, K. E. (1995) Sensemaking in organizations. Thousand Oaks: Sage Publications, Inc.
World Steel Association (2013) Steel Statistical Yearbook 2013. Recuperado em: 15 out.2015, de: http://www.worldsteel.org/statistics/statisticsarchive.html 